\title{
EFISIENSI ALAT MUAT DAN ALAT ANGKUT UNTUK PENGUPASAN OVERBURDEN PADA SITE A DI PT. SAMANTAKA BATUBARA DESA PAUH RANAP KECAMATAN PERANAP KABUPATEN INDRAGIRI HULU PROVINSI RIAU
}

\author{
Ahmad Fauzi Pohan ${ }^{1}$, Refky Adi Nata ${ }^{2}$, Ronal Floren ${ }^{3}$ \\ Teknik Pertambangan, Sekolah Tinggi Teknologi Industri Padang \\ email :1 fauzipohan@sttind.ac.id, ${ }^{2}$ refkyadinata@sttind.ac.id, 3rolanfloren@gmail.com
}

\begin{abstract}
ABSTRAK
Dalam usaha peningkatan produktifitas Overburden diperlukan rencana kebutuhan alat muat dan alat angkut yang tujuannya agar alat muat dan alat angkut yang dioperasikan mampu bekerja secara optimal sesuai dengan kondisi alat tersebut. Metode penambangan yang diterapkan di PT. Samantaka Batubara adalah cara tambang terbuka dengan penambangan konvensional yaitu dengan menggunakan kombinasi peralatan excavator dan dump truck. Menurut keputusan Bupati Indaragiri Hulu Nomor 001/IUP/545-02/II/2013 tentang persetujuan peningkatan izin usaha pertambangan eksplorasi menjadi izin usaha pertambangan operasi produksi kepada PT. Samantaka Batubara dengan luas wilayah IUP OP $19.040 \mathrm{Ha}$.
\end{abstract}

Kata kunci : Produktifitas, Metode Konvensional, PT. Samantaka Batubara Memiliki IUP OP $19.040 \mathrm{Ha}$.

\section{PENDAHULUAN}

Indonesia merupakan negara yang kaya akan sumberdaya batubara. Batubara merupakan sumber energi alternatif saat ini. Batubara sebagai salah satu sumber energi dan sebagai aset tambang yang besar di Indonesia akan semakin banyak dicari dalam upaya pemenuhan energy tersebut. Seiring dengan perkembangan dunia industri pada saat ini berakibat pula pada naiknya harga minyak dunia. Hal ini mengakibatkan kebutuhan bahan bakar untuk keperluan industri juga semakin meningkat dalam jumlah yang besar. Dengan meningkatnya harga minyak bumi, batubara mengalami peningkatan permintaan untuk bahan bakar industri.

PT. Samantaka Batubara adalah salah satu perusahaan swasta yang bergerak dalam bidang penambangan batubara ikut terdorong untuk mengoptimalkan penggalian cadangan batubara yang ada, khususnya di daerah Desa Pauh Ranap, Kecamatan Peranap, Kabupaten Indaragiri Hulu, Provinsi Riau.

PT. Samantaka Batubara menerapkan sistem tambang terbuka konvensional, dimana terdapat kombinasi antara alat gali muat (Excavator) dan alat angkut (Dump Truck). Keserasian kedua alat tersebut merupakan salah satu faktor penunjang untuk mencapai target produksi yang telah direncanakan oleh perusahaan.

\section{METODOLOGI}

\section{Gambaran Umum Wilayah Studi}

Secara administratif kegiatan di Desa Pauh Ranap Kecamatan Peranap Kabupaten. Indragiri hulu, Provinsi Riau. Yang secara geografis berada pada koordinat $00^{0} \quad 20^{\prime} \quad 57.2075^{\prime \prime}-0^{\circ} 41^{\prime}$ $56.27962^{\prime \prime}$ LS dan $102^{0} 20^{\prime} 1.9716^{\prime \prime}-101^{\circ}$ 
55' 51.47436" BT, dengan luas wilayah $19.040 \mathrm{Ha}$.

\section{Waktu dan Tempat}

Penelitian ini dilakukan pada tanggal 04 Februari - 15 Maret 2017 di PT. Samantaka Batubara Daerah Desa Pauh Ranap Kecamatan Peranap Kabupaten Indagiri hulu Provinsi Riau.

\section{Data}

Dalam penelitian ini data yang akan diambil adalah data primer dan data sekunder. Data primer yaitu data cycle time Alat angkut, data cycle time Alat Muat,data lebar jalan, data hasil survey elevasi tertinggi dan elevasi terendah suatu grade resistance, data speksifikasi alat, data perawatan alat, data curah hujan. Sedangkan data sekunder yaitu data Profil Perusahaan, Peta Topografi, Peta Geologi, Peta Lokasi penambangan, Pembagian waktu kerja (terdiri dari 2 shift).

\section{Pengolahan Data}

1. Menghitung lebar angkut pada kondisi lurus

Penentuan lebar jalan lurus didasarkan pada rule of thumb yaitu jumlah jalur yang dikali dengan lebar Dump Truck di tambah setengah lebar truck untuk masing masing tepi kiri, kanan, dan jarak antara dua dump truck yang sedang bersilang. Persamaan yang di gunakan adalah:

$$
\begin{aligned}
& \mathrm{L}(\mathrm{M})=\mathrm{n} \cdot \mathrm{Wt}+(\mathrm{n}+1)(1 / 2 . \mathrm{Wt}) \\
& \text { Penyelesaian nya: } \\
& \mathrm{Wt}=2,475 \text { meter } \\
& \mathrm{n}=2 \\
& \mathrm{~L}(\mathrm{M})=\mathrm{n} \cdot \mathrm{Wt}+(\mathrm{n}+1)(1 / 2 \cdot \mathrm{Wt}) \\
& \mathrm{L}(\mathrm{M})=2.2,475+(2+1)(1 / 2.2,475) \\
& \mathrm{L}(\mathrm{M})=9.187 \mathrm{~mm}
\end{aligned}
$$

2. Menghitung Kemiringan jalan (Grade Resistance)
Kemiringan dapat di hitung dengan menggunakan rumus Partanto Prodjosumarta, 1996.

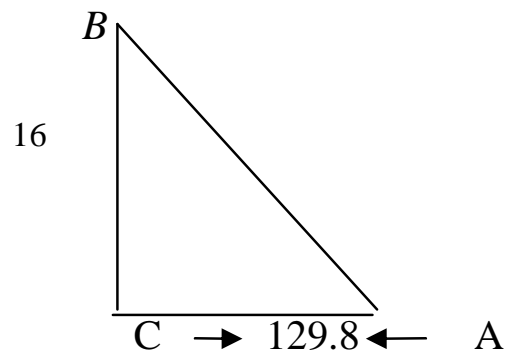

Gambar 1. Kemiringan Jalan

Penyelesaian :

Elevasi atas : 87

Elevasi bawah : 71

Jarak datar : : 129.8

$\Delta \mathrm{H}$ : Elevasi atas - elevasi bawah

$$
: 87-71=16
$$

$$
\begin{aligned}
\text { Grade Resistance }(\%) & =\frac{16}{129.8} \times 100 \% \\
& =12 \%
\end{aligned}
$$

Jika di konversi persen ke derajat, maka:

$$
\begin{aligned}
& =\frac{12 \%}{360} \times 100 \% \\
& =33.3
\end{aligned}
$$

Secara umum kemiringan jalan maksimum yang dapat di lalui dengan baik oleh alat angkut besarnya berkisar 18\%$10 \%$. Akan tetapi untuk jalan naik maupun turun pada suatu tanjakan, lebih aman kemiringan jalan maksimum sebesar $8 \%$ atau 4.5

\section{Menghitung Faktor Efisiensi Alat}

Merupakan tingkat prestasi kerja alat yang digunakan untuk melakukan produksi dari waktu yang tersedia. Cara mengetahui tingkat prestasi kerja alat dengan menggunakan Rumus Partanto Prodjosumarto (2006, hal. 178).

a. Mechanical Availability (MA)

$$
\mathrm{MA}=\frac{w}{w+K} \times 100
$$

b. Use of Utilization (UA)

$$
\mathrm{UA}=\frac{w}{w+s} \times 100 \%
$$

c. Physicall Availability (PA) 


$$
\mathrm{PA}=\frac{w+3}{w+3+K} \times 100 \%
$$

$$
\begin{aligned}
& \text { d. Effective Utilization (EU) } \\
& \mathrm{EU}=\frac{w}{w+s} \times 100 \%
\end{aligned}
$$

4. Menghitung Produktifitas Alat Muat

Pada perhitungan produksi terdapat 2 macam kemampuan alat yaitu kemampuan alat secara nyata dan kemampuan alat secara teoritis. Produksi nyata alat adalah hasil yang dapat dicapai suatu alat dalam realitas kerjanya pada saat alat itu dioperasikan. Produksi teoritis merupakan hasil terbaik secara perhitungan yang dapat dicapai alat selama waktu operasi ter-sedia, dengan memperhitungkan faktor-faktor koreksi yang ada

\begin{tabular}{|c|c|c|c|c|c|c|}
\hline No & $\begin{array}{l}\text { Jumlah } \\
\text { Bucket }\end{array}$ & $\begin{array}{c}\text { Waktu } \\
\text { Gali } \\
\text { (Detik) }\end{array}$ & $\begin{array}{c}\text { Waktu } \\
\text { Swing } \\
\text { Isi } \\
\text { (Detik) }\end{array}$ & $\begin{array}{c}\text { Waktu } \\
\text { Tumpa } \\
\text { h } \\
\text { (Detik) }\end{array}$ & $\begin{array}{c}\text { Waktu } \\
\text { Swing } \\
\text { Kosong } \\
\text { (Detik) }\end{array}$ & $\begin{array}{c}\text { Total } \\
\text { (Detik) }\end{array}$ \\
\hline 1 & 3 & 3 & 4 & 4 & 2 & 20 \\
\hline 2 & 3 & 4 & 21 & 3 & 2 & 33 \\
\hline 3 & 3 & 3 & 7 & 3 & 3 & 17 \\
\hline 4 & 3 & 4 & 5 & 4 & 3 & 21 \\
\hline 5 & 3 & 6 & 6 & 3 & 3 & 24 \\
\hline 6 & 3 & 6 & 4 & 5 & 4 & 21 \\
\hline 7 & 3 & 7 & 5 & 4 & 3 & 28 \\
\hline 8 & 3 & 5 & 4 & 5 & 3 & 21 \\
\hline 9 & 3 & 6 & 10 & 5 & 4 & 28 \\
\hline 10 & 3 & 5 & 7 & 4 & 2 & 21 \\
\hline 11 & 3 & 5 & 6 & 4 & 9 & 23 \\
\hline 12 & 3 & 3 & 8 & 5 & 5 & 21 \\
\hline 13 & 3 & 5 & 5 & 5 & 4 & 36 \\
\hline 14 & 3 & 6 & 9 & 6 & 8 & 26 \\
\hline 15 & 3 & 7 & 11 & 5 & 9 & 26 \\
\hline 16 & 3 & 6 & 10 & 6 & 6 & 28 \\
\hline 17 & 3 & 5 & 7 & 4 & 12 & 23 \\
\hline 18 & 3 & 6 & 6 & 7 & 7 & 25 \\
\hline 19 & 3 & 4 & 8 & 4 & 7 & 25 \\
\hline 20 & 3 & 4 & 6 & 6 & 5 & 21 \\
\hline $\begin{array}{l}\text { Rata- } \\
\text { rata }\end{array}$ & 3 & 5 & 7.45 & 4.6 & 5.05 & 24.4 \\
\hline
\end{tabular}

Tabel 1. Waktu siklus Excavator komatsu PC 400 no. 409

(Sumber : hasil pengamatan lapangan 2017 di PT.SBB)

\section{a. Kapasitas Alat Gali}

untuk mengetahui produktivitas alat galimuat, maka perlu dihitung kapasitas bucket, yaitu dengan persamaan (Rochmanhadi, 1992, hal 65).

$$
\begin{aligned}
\begin{array}{c}
y \\
=
\end{array} & q 1 \times K \\
\mathrm{q} & =2,2 \mathrm{~m}^{3} \times 0,9 \mathrm{BCM} / \mathrm{m}^{3} \\
& =1,98 \mathrm{LCM}
\end{aligned}
$$

b. Efisiensi Kerja

$$
\mathrm{EK}=\frac{\mathrm{Wke}}{\mathrm{Wkt}} \times 100 \%
$$

$$
\begin{aligned}
& \mathrm{EK}=\frac{2880}{3600} \times 100 \% \\
& =0.80=80 \%
\end{aligned}
$$

c. Waktu Siklus (Excavator)

$\mathrm{Ctm}=\mathrm{a}+\mathrm{b}+\mathrm{c}+\mathrm{d}$ (2.13)

$\mathrm{Ctm}=5 \mathrm{dtk}+7.45+4.6 \mathrm{dtk}+$ $5.05 \mathrm{dtk}$

$$
=22.1 \text { detik }=0.36 \text { menit }
$$

d. Produktifitas Alat Muat

$$
\begin{array}{rl}
\mathrm{Q} & =\frac{4 \times 3600 x E}{\operatorname{ctm}} \\
\mathrm{Q} & =1.98 \mathrm{M}^{3} \times 3600 \text { detik } \mathrm{x} \\
\underline{0.80} & 22.1 \mathrm{detik} \\
= & 211.57 \mathrm{BCM} / \mathrm{Jam}
\end{array}
$$

5. Menghitung Produktifitas Alat Angkut

Dalam perhitungan produktifitas alat angkut, perlu dihitung kapasitas vessel dump truck dengan persamaan (Rochmanhadi, 1992, hal 65).

a. Kapasitas Alat Angkut Gali

$$
\begin{gathered}
C=r \times \varphi 1 \times K \ldots \ldots . .(2.10) \\
\mathrm{q} \quad=2.2 \times 0,9 \mathrm{~m}^{3} \times 4 \\
=7,92 \mathrm{~m}^{3}
\end{gathered}
$$

b. Efisiensi Kerja

$$
\begin{aligned}
\mathrm{EK} & =\frac{\mathrm{wke}}{\mathrm{wkt}} \times 100 \% \\
\mathrm{EK} & =\frac{55}{60} \times 100 \% \\
& =0.91=91 \%
\end{aligned}
$$

c. Waktu siklus

$\mathrm{Cta}=\mathrm{a}+\mathrm{b}+\mathrm{c}+\mathrm{d}+\mathrm{e}+\mathrm{f}+$ (menit) ....(2.14)

$\mathrm{Cta}$

$65.02+134.85+23.06+9.45+150.15+$ 22.15 detik 


$$
=404.64 \text { detik }=6.77 \text { menit }
$$

d. Produktifitas untuk 4 unit Dump Truck (sebelum dioptimalkan).

Produktifitas alat angkut dihitung dengan rumus sebagai berikut: (Rochmanhadi, 1992, hal 65

$$
\begin{aligned}
\mathrm{P} & =\frac{\mathrm{C} \times 3600 \times \mathrm{Et}}{\mathrm{Cta}} \\
\mathrm{P} & =\frac{7,92 \mathrm{~m}^{3} \times 3600 \times 0,91}{404.68 \mathrm{dtk}} \\
& =64,11 \mathrm{LCM} / \mathrm{jam} \times \mathrm{SF} \\
& =52,57 \mathrm{BCM} / \text { jam. }
\end{aligned}
$$

e. Maka Produktifitas untuk 4 unit Dump Truck Nissan CWB 40

$$
\mathrm{P}=\text { Produksi } 1 \text { unit DT / jam } \mathrm{x} 4
$$

Unit.

$$
\begin{aligned}
& =52,57 \mathrm{BCM} / \text { jam } \times 4 \text { unit. } \\
& =210,28 \mathrm{BCM} / \mathrm{jam}
\end{aligned}
$$

6. Faktor Keserasian (Match Factor)

Macth Factor adalah keserasian kerja antara alat muat dengan alat angkut, ini dapat ditentukan dengan cara menghitung faktor keserasian (Match Factor) dari alat-alat tersebut yaitu dengan persamaan, Partanto Prodjosumarto, (1996, hal 206).

$$
\begin{aligned}
& F K(\text { Match Factor })=\frac{N a \times m x ~ C t m}{M n \times C t Q} \\
& \mathrm{Na}=4 \\
& \mathrm{Nm}=1 \\
& \mathrm{~N}=4 \\
& \mathrm{Cta}=404,68 \mathrm{dtk} \\
& \mathrm{Ctm}=22,1 \mathrm{dtk} \\
& \text { Penyelesaian: } \\
& \mathrm{MF}=\frac{4 \times 4 \times 22,1 \mathrm{dtk}}{1 \times 404,68}
\end{aligned}
$$

dtk

$$
=<0.87=<1
$$

$\mathrm{MF}<1$ kapasitas alat angkut lebih kecil dari kapasitas alat muat artinya alat muat akan sering menunggu.

\section{HASIL DAN PEMBAHASAN}

Dari hasil perhitungan sebelumnya didapatkan hasil Produktifitas Excavator PC 400 LC pada pengupasan Overburden di Site A 211.57 BCM/ Jam. Sedangkan untuk produktifitas Dump Truck Nissan
CWB n0 40 pada pengupasan Overburden di Site A 210.28 BCM/jam. Dan faktor keserasiannya 0.87 Karena $\mathrm{MF}<1$ artinya alat muat bekerja kurang dari $100 \%$ sedangkan alat angkut bekerja 100\%, sehingga terdapat waktu tunggu bagi alat muat (front loading). Maka jumlah Dump Truck yang harus dilayani satu Excavator komatsu PC 400 LC.

$$
\begin{aligned}
\mathrm{Na} & =\frac{\mathrm{MF} \times \mathrm{Nm} \times \mathrm{Cta}}{\mathrm{N} \times \mathrm{Ctm} .} \\
& =\frac{1 \times 1 \times 6.77 \mathrm{mnt}}{4 \times 0,36 \mathrm{mnt}} \\
\mathrm{Na} & =4.70 \text { unit } \sim 5 \text { unit } .
\end{aligned}
$$

Produktifitas Excavator Komatsu PC 400 LC dan Dump Truck Nissan CWB sesudah dioptimalkan

a. Produksivitas Excavator Komatsu PC 400 LC

$$
\begin{aligned}
Q & =\frac{\mathrm{q} \times 3600 \times \mathrm{E}}{\mathrm{Ctm}} \\
& =\frac{1,98 \mathrm{~m}^{3} \times 3600 \mathrm{dtk} \times 1}{22.1 \mathrm{dtk}} \\
& =322,53 \mathrm{LCM} / \mathrm{Jam} \times \mathrm{SF}
\end{aligned}
$$

$(0,82)$

$$
\text { = 264,47 BCM/ Jam. }
$$

b. Produksivitas Dump Truck Nissan CWB 40

$$
\begin{aligned}
\mathrm{P} & =\frac{\mathrm{q} \times 3600 \times \mathrm{E}}{\mathrm{Cta}} \\
& =\frac{7,92 \mathrm{~m}^{3} \times 3600 \times 0,91}{404.68 \mathrm{dtk}} \\
& =64,11 \mathrm{LCM} / \mathrm{jam} \times \mathrm{SF}(0,82) \\
& =52,57 \mathrm{BCM} / \mathrm{jam} .
\end{aligned}
$$

Maka produktivitas untuk 5 unit Dump Truck Nissan CWB 40:

$$
\begin{aligned}
\mathrm{P} & =\text { Produksi } 1 \text { unit DT / jam x } 5 \text { Unit. } \\
& =52,57 \mathrm{BCM} / \text { jam } x 5 \text { unit. } \\
& =262.85 \mathrm{BCM} / \mathrm{jam}
\end{aligned}
$$

Faktor Keserasian Match Factor (MF)

Keserasian kerja antara alat muat dan alat angkut:

$$
\begin{aligned}
\text { MF } & =\frac{5 \times 3 \times 22.1 \mathrm{dtk} .}{1 \times 404,68 \mathrm{dtk}} \\
& =1,09=1 .
\end{aligned}
$$


Untuk Rekapitulasi kondisi Sebelum dan Sesudah dioptimalkan Excavator dan Dump Tuck dapat dilihat

Tabel 2. Kondisi Sebelum dan Sesudah dioptimalkan Excavator dan Dump Truck.

\begin{tabular}{|l|ll|l|}
\hline Kondisi & $\begin{array}{l}\text { Produktivitas } \\
\text { Exacavator }\end{array}$ & $\begin{array}{l}\text { Produktivitas } \\
\text { pump Truck }\end{array}$ & $\begin{array}{l}\text { Match } \\
\text { Factor } \\
\text { MF) }\end{array}$ \\
\hline $\begin{array}{l}\text { Sebelum di } 211.57 \\
\text { pptimalkan }\end{array}$ & 3CM/Jam & 3CM/Jam & 3C. 10.28 \\
\hline $\begin{array}{l}\text { Setelah di } 264.47 \\
\text { pptimalkan }\end{array}$ & 3CM/Jam & 3C2.85 $/ \mathrm{Jam}$ & $1,09=1$ \\
\hline
\end{tabular}

\section{KESIMPULAN DAN SARAN}

\section{Kesimpulan}

Berdasarkan uraian dan perhitungan dari bab sebelumnya, maka dapat diambil kesimpulan sebagai berikut:

1. Proses penambangan PT. Samantaka Batubara merapakan sistem tambang terbuka konvensional, dimana terdapat Kombinasi alat-alat mekanis berupa alat gali muat dan alat angkut.

2. Produksifitas alat muat Excavator Komatsu sebelum dioptimalkan sebesar 211.57 BCM/Jam. dan produktivitas Dump Truck Nissan CWB untuk 4 unit sebelum dioptimalkan sebesar 210.28 $\mathrm{BCM} / \mathrm{jam}$, sedangkan faktor keserasiannya sebelum dioptimalkan adalah 0,87 .

3. Produktifitas alat muat Excavator Komatsu setelah dioptimalkan sebesar 264.47 BCM/Jam. dan produksifitas Dump Truck Nissan CWB untuk 5 unit sebesar 262.85 BCM/jam, sedangkan faktor keserasiannya (MF) sebelum dioptimalkan adalah $1,09=1$

\section{Saran}

1. Diperlukan pengawasan yang lebih ketat terhadap waktu kerja yang telah ditetapkan guna mencegah waktu hambatan yang terjadi selama bekerja, karena waktu kerja efektif akan mempengaruhi kemampuan produksi alat mekanis (backhoe-dump truck) yang dioperasikan.
2. Untuk mengatasi waktu tunggu bagi alat muat (Excavator). Solusinya adalah dengan membuat landai Grade jalan dan memperbaiki jalan yang rusak seperti menimbun jalan-jalan yang berlubang dan diratakan supaya tidak memerlukan waktu terlalu lama untuk menunggu bagi Excavator, setelah dilakukan perbaikan jalan Dump Truck bisa lebih cepat dari pada biasanya, baik tanpa muatan ataupun sedang bermuatan.

3. Perawatan alat-alat mekanis dan jalan yang digunakan harus ditingkatkan agar dapat mendukung dalam pencapaian target produksi, selain itu ada baiknya jalan tambang dilengkapi rambu-rambu untuk meningkatkan keselamatan kerja di PT. Samantaka Batubara.

4. Perlunya kedisiplinan kepada para pekerja dan juga mewajibkan para pekerja untuk tepat waktu dalam masuk kerja.

\section{DAFTAR PUSTAKA}

Komatsu, Hidraulic Excavator Handbook, Edition 1.

Hustrulid, Pemindahan tanah mekanis Depertemen Pekerjaan Umum, Jakarta, 1995

Yanto, Indonesianto, Pemindahan Tanah Mekanis, Jurusan Teknik Pertambangan, UPN "Veteran", Yogyakarta, 2005.

Partanto, Projosumarto, Pemindahan Tanah Mekanis, JurusanTeknik Pertambangan ITB, Bandung, 1996.

Rochmanhadi, "Kapasitas dan Produksi alat-alat Berat".Depertemen Pekerjaan Umum, Jakarta, 1992. 